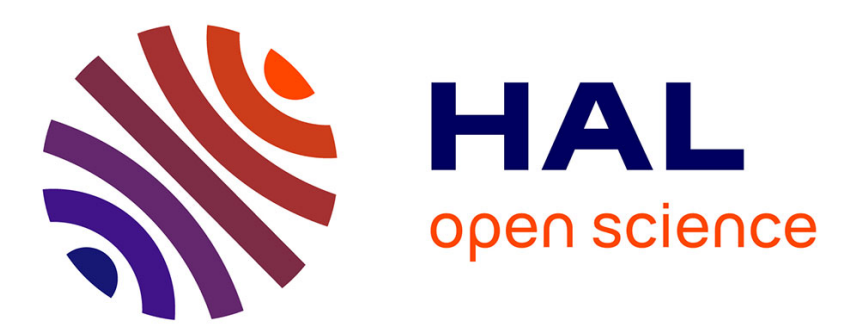

\title{
Mechanisms of Binder Removal Involved in Supercritical Debinding of Injection Moulded Ceramics
}

\author{
Thierry Chartier, Eric Delhomme, Jean-François Baumard
}

\section{To cite this version:}

Thierry Chartier, Eric Delhomme, Jean-François Baumard. Mechanisms of Binder Removal Involved in Supercritical Debinding of Injection Moulded Ceramics. Journal de Physique III, 1997, 7 (2), pp.291-302. 10.1051/jp3:1997122 . jpa-00249578

\section{HAL Id: jpa-00249578 https://hal.science/jpa-00249578}

Submitted on 1 Jan 1997

HAL is a multi-disciplinary open access archive for the deposit and dissemination of scientific research documents, whether they are published or not. The documents may come from teaching and research institutions in France or abroad, or from public or private research centers.
L'archive ouverte pluridisciplinaire HAL, est destinée au dépôt et à la diffusion de documents scientifiques de niveau recherche, publiés ou non, émanant des établissements d'enseignement et de recherche français ou étrangers, des laboratoires publics ou privés. 


\title{
Mechanisms of Binder Removal Involved in Supercritical Debinding of Injection Moulded Ceramics
}

\author{
Thierry Chartier $\left({ }^{*}\right)$, Eric Delhomme and Jean-François Baumard \\ Laboratoire des Matériaux Céramiques et Traitements de Surface $\left({ }^{* *}\right)$, ENSCI, \\ 87065 Limoges, France
}

(Received 21 March 1996, revised 17 September 1996, accepted 6 November 1997)

PACS.81 20.Hy - Forming; molding, extrusion etc.

PACS 81.20.Zx - Other methods of materials synthesis and materıals processing

\begin{abstract}
Extraction of organic additives from extrusion-moulded ceramic parts by supercritical carbon doxide has proved to be an efficient method for debinding [1,2]. A model of binder extraction based on diffusion equations was developed. This model was found to be in fair agreement with experimental results. Experimental kinetics of extraction of low melt point paraffins, by supercritical fluids, from injection-moulded samples are now established A redistribution of the bunder in the liquid state in the porosity of the sample, during supercritical debindıng, is put in evidence. The importance of this mechanism and its influence on the validity of the model are discussed
\end{abstract}

Résumé. - Des études précédentes [1,2] ont montré l'intérêt de l'extraction, à l'alde de gaz carbonique dans l'état supercritique, des additifs organıques de mise en forme de pièces céramiques. Elles ont permis de développer un modèle, établı à partir des équations de diffusion, quı est en bon accord avec les résultats expérımentaux. Les cınétiques expérimentales d'extraction, par fluide supercritique, de paraffines à bas point de fusion utılisées comme liant pour des compositions d'injection sont maintenant étudiées Une redistributıon du liant à l'état liquide au sein de la porosité de l'échantillon pendant le déliantage supercritıque est mise en évidence. L'ımportance de ce mécanısme et son influence sur la validité du modèle sont discutées.

\section{Introduction}

Most high technology ceramic processing like dry-pressing, tape-casting, injection or extrusionmoulding requires the use of organic compounds as dispersants, binders, plasticizers and so on, to confer such properties as cohesion, flexibility and workability in the green state. Amounts as large as $50 \mathrm{vol} . \%$ of organics are sometimes added to the ceramic powder during the forming step, and have to be removed prior to sintering. Thermal debinding, which is currently used, remains one of the most critical phases of ceramic processing, particularly for large size parts [3-6], and requires slow heating rates, thus being time consuming. It may also lead to defects which are detrimental to the properties of the sintered material [7].

$\left({ }^{*}\right)$ Author for correspondence

$\left({ }^{* *}\right)$ URA CNRS 320

(C) Les Éditions de Physique 1997 
Table I. - Typical values of the viscosity $\eta$, the density $\rho$ and the self-diffusion coefficient $D_{\mathrm{s}}$ for some common gases, supercritical fluids and liquids.

\begin{tabular}{|lccc|}
\hline & $\rho\left(\mathrm{g} \mathrm{cm}^{-3}\right)$ & $\eta(\mathrm{mPa} \mathrm{s})$ & $D_{\mathrm{s}}\left(\mathrm{m}^{2} \mathrm{~s}^{-1}\right)$ \\
\hline gases, $1 \mathrm{~atm}, 15-30^{\circ} \mathrm{C}$ & $(0.6-2) \times 10^{-3}$ & $(1-3) \times 10^{-2}$ & $(0.1-0.4) \times 10^{-4}$ \\
supercritical fluids ${ }^{(*)}$ & & & \\
$T_{\mathrm{c}}, P_{\mathrm{c}}$ & $0.2-05$ & $(1-3) \times 10^{-2}$ & $0.7 \times 10^{-7}$ \\
$T_{\mathrm{c}}, 4 P_{\mathrm{c}}$ & $04-0.9$ & $(3-9) \times 10^{-2}$ & $0.2 \times 10^{-7}$ \\
liquids, $1 \mathrm{~atm}, 15-30^{\circ} \mathrm{C}$ & $0.6-1.6$ & $0.2-3$ & $(0.2-2) \times 10^{-9}$ \\
\hline
\end{tabular}

${ }^{(*)} T_{\mathrm{c}}$ and $P_{\mathrm{c}}$ are the critical temperature and pressure of the fluid.

Extraction of binders by supercritical fluids, based on the dissolving characteristics and transport properties of fluids at temperatures and pressures beyond the critical point, thus appears to be an interesting alternative to reduce debinding time and to produce defect-free green bodies. Some typical features of supercritical fluids [8] are listed in Table I. While the densities of liquids and supercritical fluids are more or less similar, the self-diffusion coefficients are expected to be much larger in the latter media.

A first study dealing with supercritical debinding kinetics was performed on extrusionmoulded alumina cylinders [1]. It showed that two mechanisms were involved in the extraction process' solubilisation of soluble binder molecules and diffusion of these solubilised species (called solvato-complexes). A model based on diffusion equations was thus developed.

In the present work, we continue to investigate the different debinding mechanisms and to test the validity of this model. This time however, samples used are obtained by low pressure injection of a mixture of alumina and two paraffins. As the paraffins used melt at a low temperature, an additional mechanism of extraction by capillary migration can take place within the sample during the extraction process. Its influence on extraction rate and porosity development is thus studied in order to determine if the model can still be applied even when capillary flow is present.

\section{Experimental Procedure}

Carbon dioxide, extensively used in the food or perfume industry, has shown promising possibilities for extraction of light organic compounds in ceramic forming processes $[9,10]$. Main advantages of carbon dioxide lie in a low cost as well as in the absence of toxicity and flammab1lity. The equipment used for this study has already been described in reference [1] and [2]. The extraction can be operated up to $30 \mathrm{MPa}$, at temperatures ranging from 30 to $120^{\circ} \mathrm{C}$. The cell temperature is regulated within $\pm 1^{\circ} \mathrm{C}$ and the pressure within $\pm 0.2 \mathrm{MPa}$. The high pressure membrane pump can supply up to 5 liters $\mathrm{CO}_{2}$ (or 3 to $4.5 \mathrm{~kg}$ according to the pressure) per hour. The flow rate used during the experiments was set to $2.5 \mathrm{l} \mathrm{h}^{-1}$, which avoids any problem of confinement

The samples investigated here are injection-moulded bars made from an alumina powder consisting in a mixture of different granulometric distributions and two types of paraffin, one melting at $54^{\circ} \mathrm{C}$, the other at $64^{\circ} \mathrm{C}$.

These paraffins are introduced in equal quantities in a Dupplex-Kneter mixer preheated at $100{ }^{\circ} \mathrm{C}$. Once wax has melted, alumina is added and the batch is mixed for one hour under vacuum. The resulting mix is injected in a mould under a $06 \mathrm{MPa}$ low pressure. Finally, a cold water circulation through the mould ensures solidification of the mix. Injected plates 


\section{Supercritical Debinded Sample}

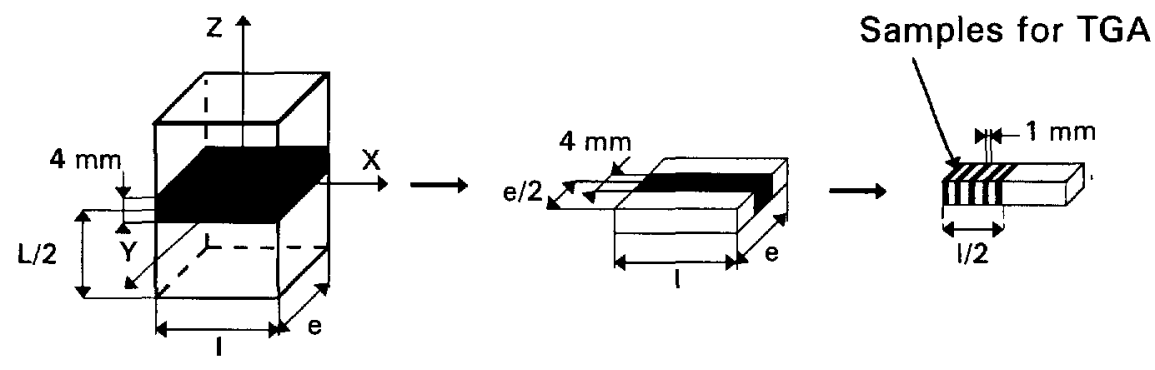

Fig. 1 - Location of the parts cut in debinded samples and used for the thermogravimetric analysis.

$\left(150 \times 150 \times 20 \mathrm{~mm}^{3}\right)$, in which paraffins fill the porosity of the ceramic bulk (porosity of $16.5 \mathrm{vol} . \%$ with a mean pore diameter of $1 \mu \mathrm{m}$ ), are thus obtained.

Bars are cut in these plates to the desired dimensions, i.e. $10 \times 25 \times 40 \mathrm{~mm}^{3}$ for porosity analysis or $20 \times 25 \times 40 \mathrm{~mm}^{3}$ for the study of binder distribution that requires thicker samples.

Samples to be debinded are introduced in a cylindrical basket once weighted. This basket, fitted with sintered metallic parts at both ends, acts as a sample holder for the polymercontaining materials, and remains permeable to the fluids. It is put in position into the extractor and submitted to a flow of supercritical $\mathrm{CO}_{2}$.

The experimental extraction rate $\beta$, after a treatment time $t$, is estimated from the weight change $\Delta M(t)$ of the sample:

$$
\beta=\frac{\Delta M(t)}{C_{0} M_{1}}
$$

where $M_{\mathrm{i}}$ is the initial weight of the sample and $C_{0}$ is the initial concentration of binder.

Samples were debinded under pressures of $16,20,24$ and $28 \mathrm{MPa}$, at temperatures of 52,62 and $72{ }^{\circ} \mathrm{C}$, for one, two and three hours.

Pore size distributions were obtained by mercury porosimetry (Autopore II, Micromeritics, France) on the thinner samples.

The experimental binder distribution was determined by analysing the weight loss of small parts cut in the thicker bars already debinded as shown in Figure 1. Typical dimensions of these parts are $4 \times 4 \times 1 \mathrm{~mm}^{3}$. Thermogravimetric analysis (L81, Linseis, Germany) were performed with an heating rate of $5{ }^{\circ} \mathrm{C} \mathrm{min}^{-1}$ up to $500^{\circ} \mathrm{C}$ and an hold time of 5 minutes at this temperature.

\section{Theoretical Background}

When supercritical $\mathrm{CO}_{2}$ is allowed to enter the basket, it immediately diffuses in the whole sample. $\mathrm{CO}_{2}$ molecules form weak van der Waals type bonds with paraffin chains creating "solvato-complexes" which diffuse through the porosity of the sample to the surface. The solubility aspect will however be the topic of a further study. Solubilisation of wax and diffusion take place simultaneously. As binder is removed from the body, a non-planar diffusing front is created in the sample. According to the previous work [1], it has been shown that diffusion is the limiting step for the extraction of soluble paraffin. 
Polymer diffusion through a parallelepipedic porous sample defined by its length $L$, width $l$ and thickness $e$, is modelled in terms of the local polymer content $C(x, y, z, t)$ in the body, which is assumed to vary according to the classical diffusion equation:

$$
\frac{\partial C(x, y, z, t)}{\partial t}=D\left(\frac{\partial^{2}(x, y, z, t)}{\partial x^{2}}+\frac{\partial^{2} C(x, y, z, t)}{\partial y^{2}}+\frac{\partial^{2} C(x, y, z, t)}{\partial z^{2}}\right),
$$

$D$ being the diffusivity of the polymer $\left(\mathrm{m}^{2} \mathrm{~s}^{-1}\right)$.

The initial and boundary conditions are expressed as:

- concentration $C(x, y, z, 0)=C_{0}$;

- no binder at the surface during extraction (immediate evacuation): $C\left(L^{\prime}, l^{\prime}, h^{\prime}, t\right)=0$ with $L^{\prime}=L / 2, l^{\prime}=l / 2$ and $e^{\prime}=e / 2$;

- $\partial C(x, y, z, t) / \partial x=0$ for $x=0, \partial C(x, y, z, t) / \partial y=0$ for $y=0, \partial C(x, y, z, t) / \partial z=0$ for $z=0$.

Integration of equation (2) gives the content of polymer which subsists in the green body after a given time $t$ of extraction. Under the assumption that the diffusivity $D$ is a constant, the problem is similar to that of heat conduction and the polymer content can be expressed by [11]:

$$
\begin{aligned}
\frac{\partial C(x, y, z, t)}{C_{0}}= & \frac{64}{\pi^{3}} \sum_{i=0}^{\infty} \sum_{\jmath=0}^{\infty} \sum_{k=0}^{\infty} \frac{(-1)^{2+\jmath+k}}{(2 i+1)(2 j+1)(2 k+1)} \\
& \times \cos \frac{(2 i+1) \pi x}{2 L^{\prime}} \cos \frac{(2 \jmath+1) \pi y}{2 l^{\prime}} \cos \frac{(2 k+1) \pi z}{2 h^{\prime}} \exp \left(-\alpha_{\imath, \jmath, k} t\right)
\end{aligned}
$$

with:

$$
\alpha_{\imath, \jmath, k}=\frac{D \pi^{2}}{4}\left(\frac{(2 \imath+1)^{2}}{L^{\prime 2}}+\frac{(2 \jmath+1)^{2}}{l^{\prime 2}}+\frac{(2 k+1)^{2}}{h^{\prime 2}}\right) .
$$

The mean concentration $C_{t}$ at a given time $t$ is obtained by: $C_{t}=\frac{\int C(x, y, z) \mathrm{d} x \mathrm{~d} y \mathrm{~d} z}{\int \mathrm{d} x \mathrm{~d} y \mathrm{~d} z}$ Thus:

$$
\frac{C_{t}}{C_{0}}=\frac{512}{\pi^{6}} \sum_{\imath=0}^{\infty} \sum_{j=0}^{\infty} \sum_{k=0}^{\infty} \frac{\exp \left(-\alpha_{\imath, j, k} t\right)}{((2 \imath+1)(2 j+1)(2 k+1))^{2}} .
$$

$C_{t} / C_{0}$ can also be expressed as a function of the extraction rate $\beta$.

$$
\beta=1-\frac{C_{t}}{C_{0}}
$$

After long times of extraction (more than 2 hours) the first term of equation (4) $(i=j=k=0$ ) prevails and the extraction rate is finally given by:

$$
\ln \beta=\ln \left(1-\frac{512}{\pi^{6}} \exp \left(-\frac{\pi^{2}}{4}\left(\frac{1}{L^{\prime 2}}+\frac{1}{l^{\prime 2}}+\frac{1}{h^{\prime 2}}\right) D \times t\right)\right) .
$$

\section{Results and Discussion}

4.1. Solubility. - Supercritical $\mathrm{CO}_{2}$ is a good solvent for polymers possessing non polar groups and/or a low molecular weight, such as alkanes and terpenes. It is fairly good for moderately polar species but becomes less efficient for compounds with polar groups and/or high molecular weight [12]. 
DENSITY $(\mathrm{kg} / \mathrm{m3})$

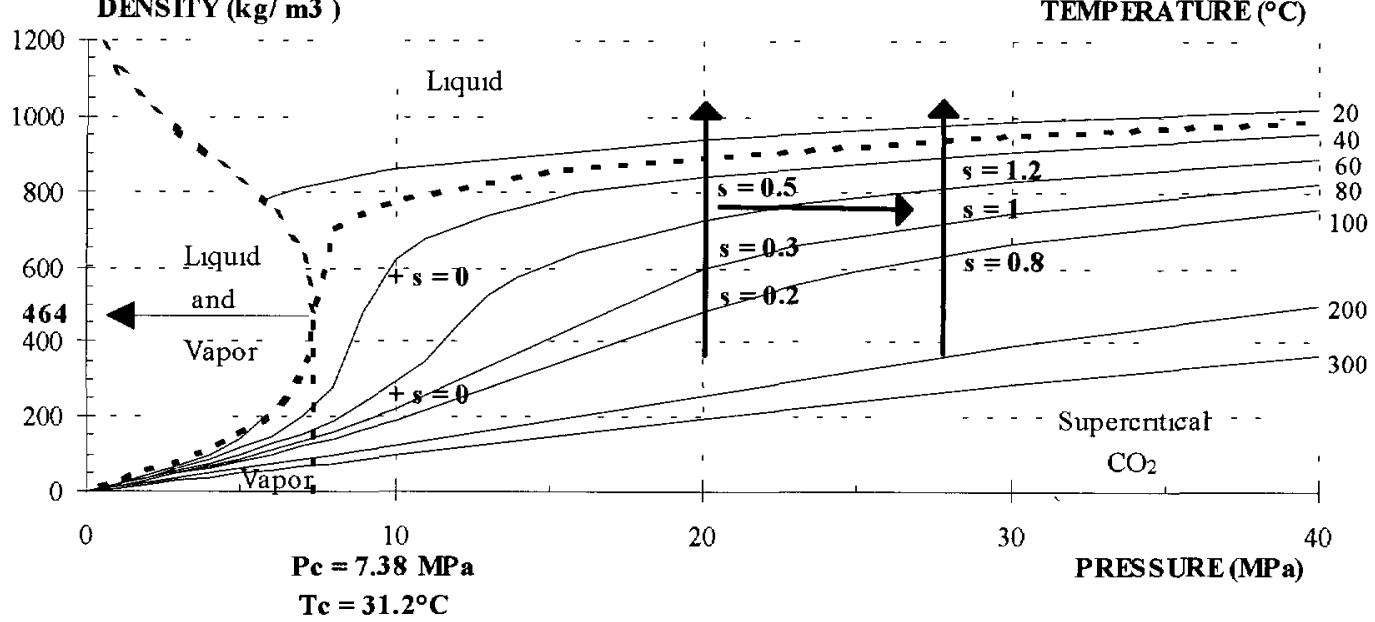

Fig. 2. - Phase diagram of carbon dioxide with experimentally determined solubllity $s$ of the paraffin mix ( $s \cdot$ mass of paraffin dissolved in $100 \mathrm{~g}$ of $\mathrm{CO}_{2}$ ).

An attempt was done to determine the solubility of both paraffins in supercritical $\mathrm{CO}_{2}$ with our device for different temperature and pressure conditions. A given amount of paraffin was placed in the cylindrical basket and submitted to a flow of carbon dioxide. The solubility of paraffin is then evaluated by dividing the mass of paraffin removed during a 15 minutes treatment by the corresponding mass of flowing $\mathrm{CO}_{2}$. Values of solubility are reported in the phase diagram (Fig. 2).

Depending on pressure and temperature, supercritical $\mathrm{CO}_{2}$ can prove to be a relatively good solvent for paraffin. Unfortunately, our results are not sufficiently accurate as the device does not include an equilibrium cell for phase diagram investigations. Nevertheless, their interest is to show the trends of paraffin solubility versus pressure and temperature. As clearly shown in Figure 2, the largest solubility corresponds to the largest density of $\mathrm{CO}_{2}$ reached during the present work.

4.2. Diffusivity. - Using the value of the mass $\Delta M$ extracted after a debinding time of three hours, the extraction rate $\beta$ has been determined with equation (1) for each experimental condition. The values of diffusivity $D$ of dissolved organics, reported in Table II, are then calculated under different experimental conditions using equation (5). Pressure and temperature dependencies of $D$ are plotted in Figures 3 and 4.

Equation (4) can then be used to calculate theoretical values of extraction for smaller times of treatment. An example of debinding kinetics is given in Figure 5 for the $52{ }^{\circ} \mathrm{C}$ case.

The paraffin content decreases progressively with time and reaches a plateau which does not correspond to a complete extraction even after prolonged experiments. The molecular weight distribution of paraffin is large, and probably the lighter backbones only can be dissolved. This is the reason why the following discussions will concern the soluble fraction of the binder mix only. The insoluble part remains present in the porosity of the ceramic green body.

Under constant pressure, the diffusivity is thermally activated in the range of temperature investigated. Under constant temperature, the diffusivity increases with pressure, excepted at $52^{\circ} \mathrm{C}$ under $28 \mathrm{MPa}$ (Fig. 3). 


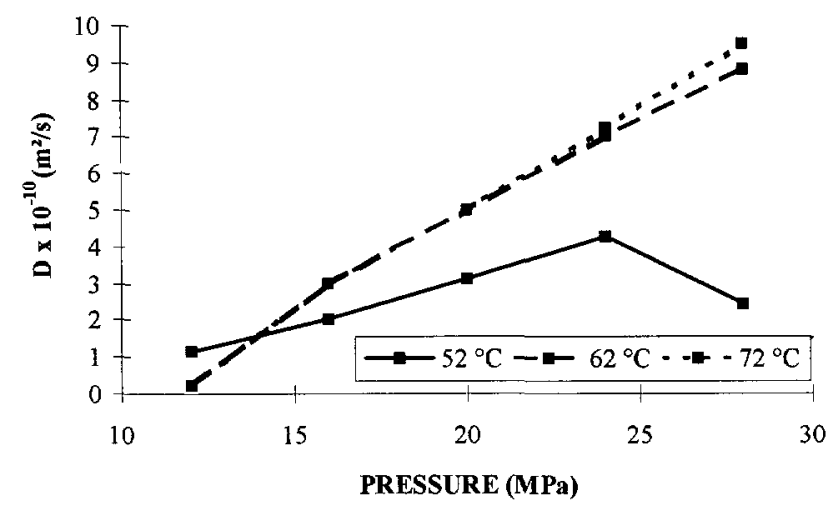

Fig 3. - Evolution of diffusivity with pressure for different temperatures.

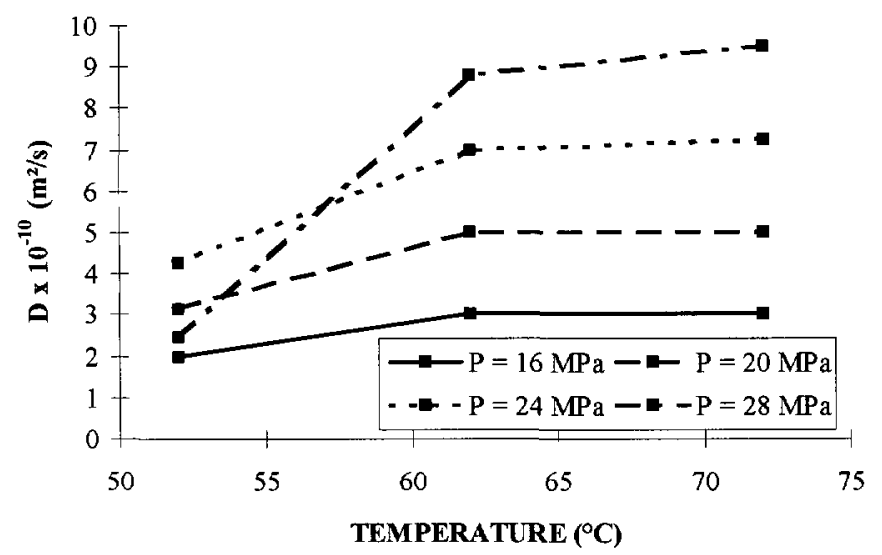

Fig. 4. - Evolution of diffusivity with temperature for different pressures

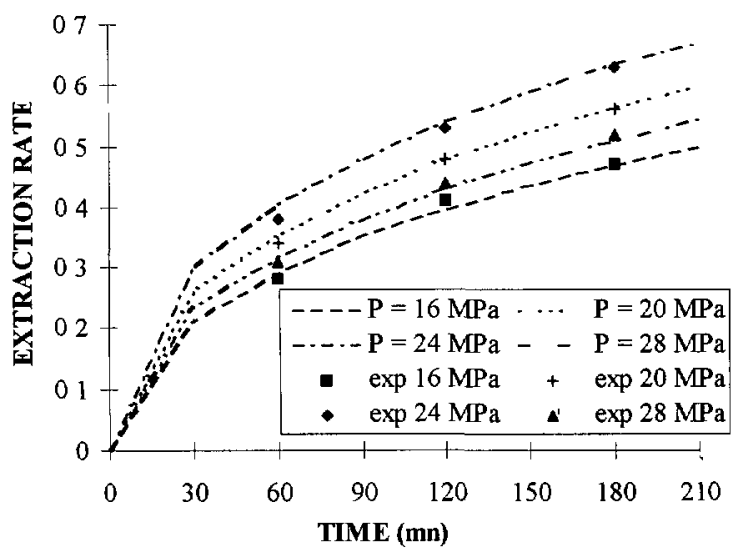

Fig 5. - Kinetics of binder extraction obtained at $52{ }^{\circ} \mathrm{C}$ for different pressures (theoretical kinetics in dotted lines and experimental points). 
Table II. - Values of diffusivnty $D$ experimentally determined.

\begin{tabular}{|c|ccc|}
\hline \multicolumn{3}{|c|}{ Diffusivity $\left(\times 10^{-10} \mathrm{~m}^{2} \mathrm{~s}^{-1}\right)$} \\
\hline$P(\mathrm{MPa})$ & \multicolumn{3}{|c|}{$\left.T{ }^{\circ} \mathrm{C}\right)$} \\
& 52 & 62 & 72 \\
\hline 16 & 2.0 & 3.0 & 3.0 \\
20 & 3.1 & 5.0 & 5.0 \\
24 & 4.2 & 7.0 & 7.2 \\
28 & 24 & 8.8 & 9.5 \\
\hline
\end{tabular}

The diffusivity depends on polymer solublity and diffusion of dissolved molecules, and both quantities are influenced by pressure and temperature. Diffusion as given by the Wilke and Chang equation [13], increases when temperature increases or pressure decreases, whereas solublity increases when temperature decreases or pressure increases.

Diffusivity variations with temperature and pressure are thus a balance between the variations of the amount of solubilised molecules and the diffusion of these species. The diffusivity increase with pressure can result from a solubility increase: more species are diffusing leading to an increase in the final extracted mass The diffusivity decrease at $52{ }^{\circ} \mathrm{C}$ for pressures higher than $24 \mathrm{MPa}$ may be the consequence of a too strong decrease in velocity. The diffusivity increase with temperature can be a consequence of a faster diffusion of dissolved wax molecules.

However, as temperature is raised above the melting point of the paraffins used in this study $\left(54^{\circ} \mathrm{C}\right.$ and $64{ }^{\circ} \mathrm{C}$ ), a liquid phase develops in the sample during binder removal. Then, liquid phase transport due to capillary migration is likely to occur leading to a redistribution of the binder within the sample.

4.3. Distribution of Soluble Binder After Debinding. - This eventual redistribution of the organic phase during debinding has been experimentally verified by thermogravimetric analysis (TGA) on thicker bars debinded under $28 \mathrm{MPa}$, at 52,62 and $72{ }^{\circ} \mathrm{C}$, for two hours.

Using the values of diffusivity determined above, equation (3) allows to calculate the residual amount of soluble binder in the green body after a given time $t$ of treatment as a function of the $x, y, z$ coordinates. As the initial binder amount is known and supposed to be the same throughout the green body before the treatment, we can derive, from the above values, the loss of soluble binder after the same time $t$ of treatment as a function of the $x, y, z$ coordinates. These theoretical values can be compared to the experimental ones derived from the TGA measurements. As there is an evident central symmetry in binder distribution whatever the extraction time considered, we only consider values corresponding to the small parts located between 0 and $l / 2$ (Fig. 1). Five values are thus obtained with $x_{c}$ equal to 05 (centre), 3, 5.5, 8 and 10.5 (surface) $\mathrm{mm}$.

Theoretical and experimental percentages of soluble binder removed are given in Table III. They agree very well at $52{ }^{\circ} \mathrm{C}$, whereas they are quite different at 62 and $72^{\circ} \mathrm{C}$.

At $52{ }^{\circ} \mathrm{C}$, the binder phase is solid and solubilised wax molecules can only be evacuated by diffusion in the porosity which develops as wax is removed from the green body. As diffusion is the only mechanism occurrmg at this temperature, equations (4) and (5) based on Fick's diffusion laws are particularly well suited to this case. 
Table III. - Theoretical and experimental percentages of soluble binder losses (28 MPa, $2 \mathrm{~h}$ ).

\begin{tabular}{|lcccccc|}
\hline \multicolumn{1}{|c}{$\begin{array}{c}\text { Debinding } \\
\text { temperature }\end{array}$} & \multicolumn{2}{c}{$52{ }^{\circ} \mathrm{C}$} & \multicolumn{2}{c}{$62^{\circ} \mathrm{C}$} & \multicolumn{2}{c|}{$72{ }^{\circ} \mathrm{C}$} \\
\hline Part location: $x_{\mathrm{c}}$ & th. val & exp. val. & th. val. & exp. val. & th. val. & exp. val. \\
\hline $0.5 \mathrm{~mm}$ (center) & 0 & 0 & 0.9 & 7.6 & 1.8 & 51.1 \\
$3 \mathrm{~mm}$ & 0 & 0 & 4.5 & 10.3 & 12.2 & 52.5 \\
$5.5 \mathrm{~mm}$ & 16 & 2.8 & 17 & 31 & 27.6 & 51.3 \\
$8 \mathrm{~mm}$ & 18.6 & 20 & 465 & 49 & 55 & 60.3 \\
$10.5 \mathrm{~mm}$ (surface) & 50 & 50 & 85 & 43.5 & 90.1 & 49.5 \\
\hline
\end{tabular}

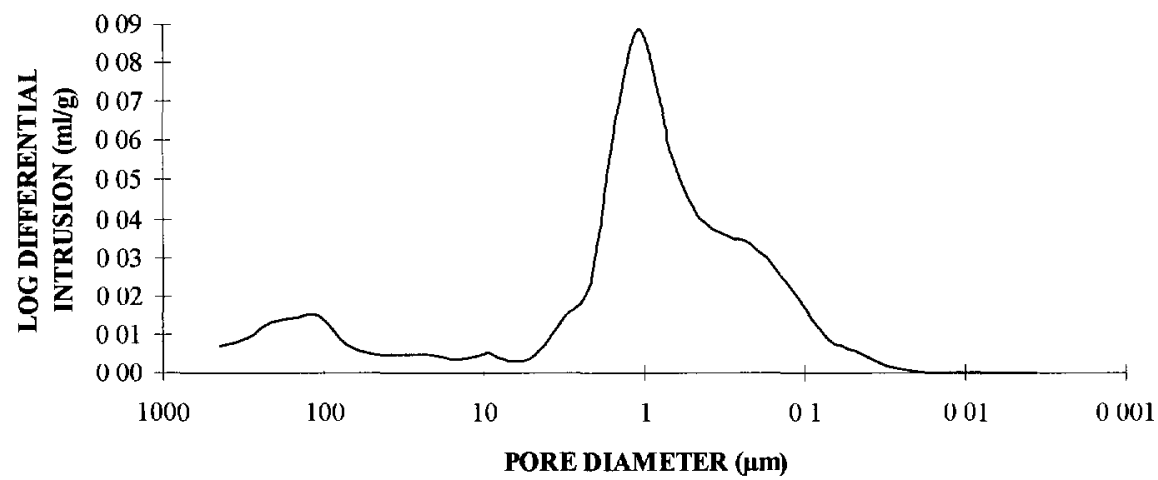

Fig 6. - Pore size distribution of a completely thermally debinded sample.

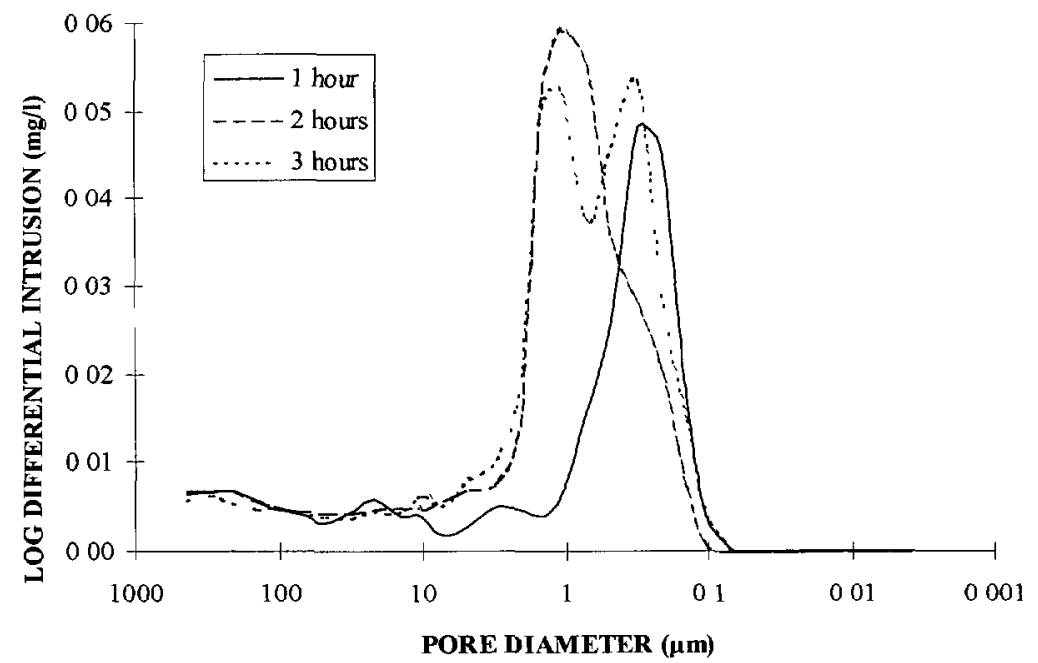

Fig 7 - Porosity development of a sample debinded under $28 \mathrm{MPa}$, at $52{ }^{\circ} \mathrm{C}$ for a) 1 hour, b) 2 hours and c) 3 hours 


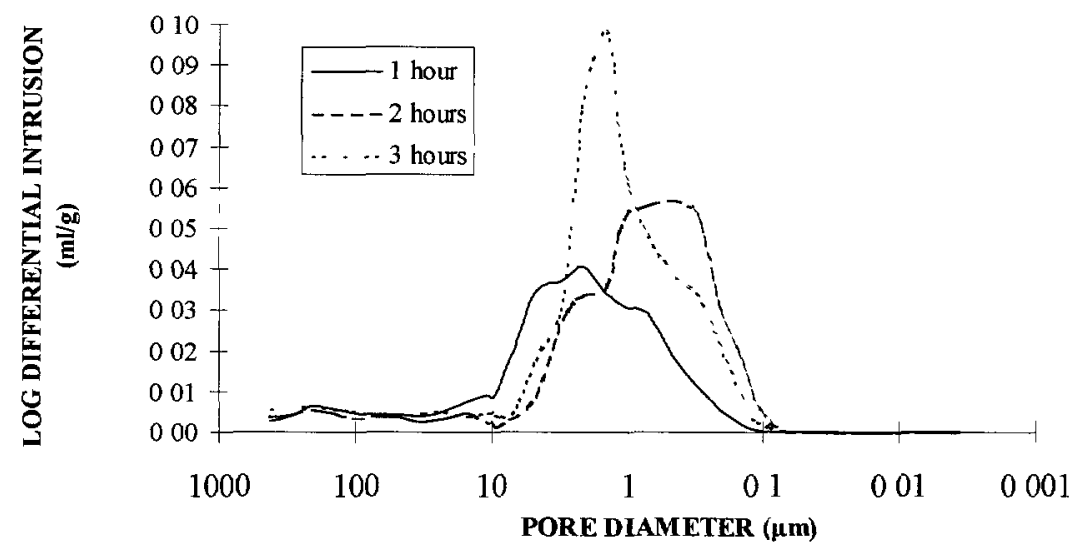

Fig. 8. - Porosity development of a sample debinded under $28 \mathrm{MPa}$, at $62{ }^{\circ} \mathrm{C}$ for: a) 1 hour, b) 2 hours and c) 3 hours

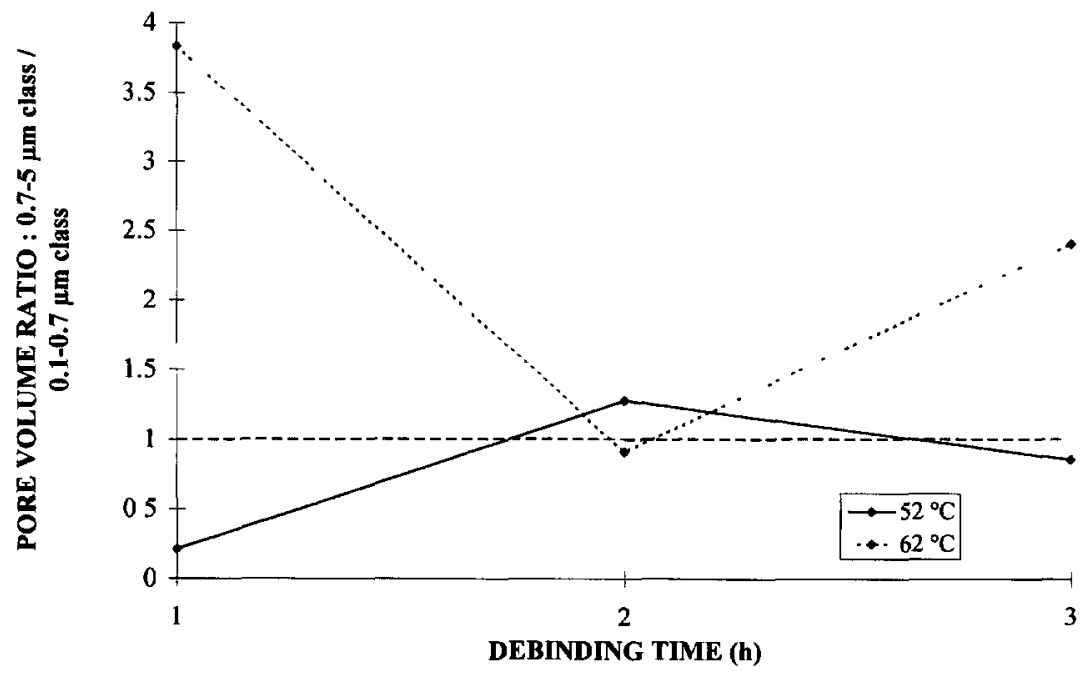

Fig 9 - Variation of the volume ratio of pores between 0.7 and $5 \mu \mathrm{m}$ over pores between 0.1 and $07 \mu \mathrm{m}$ as a function of time at $52{ }^{\circ} \mathrm{C}$ and $62{ }^{\circ} \mathrm{C}$ under $28 \mathrm{MPa}$

At $62{ }^{\circ} \mathrm{C}$ and $72{ }^{\circ} \mathrm{C}$ however, the calculated binder loss distribution in the sample does not fit anymore the experimental one. Binder loss throughout the sample is more uniform than predicted by the diffusion model which may be due to a liquid phase redistribution. As the temperature is now higher than the melting point of the paraffin mix (measured equal to $56{ }^{\circ} \mathrm{C}$ on a torque rheometer), liquid wax is able to move from the heart to the surface of the sample where it is removed by the supercritical fluid flow. As shown by Cima et al. [14], the driving force responsible for such a flow is given by the difference in capillary pressure $\Delta P$ resultıng from the different pore radii present in the sample:

$$
\Delta P=2 \gamma \cos \theta\left(\frac{1}{R_{1}}-\frac{1}{R_{2}}\right)
$$

where $\gamma$ is the surface tension of the liquid, $\theta$ is the contact angle between the liquid and 


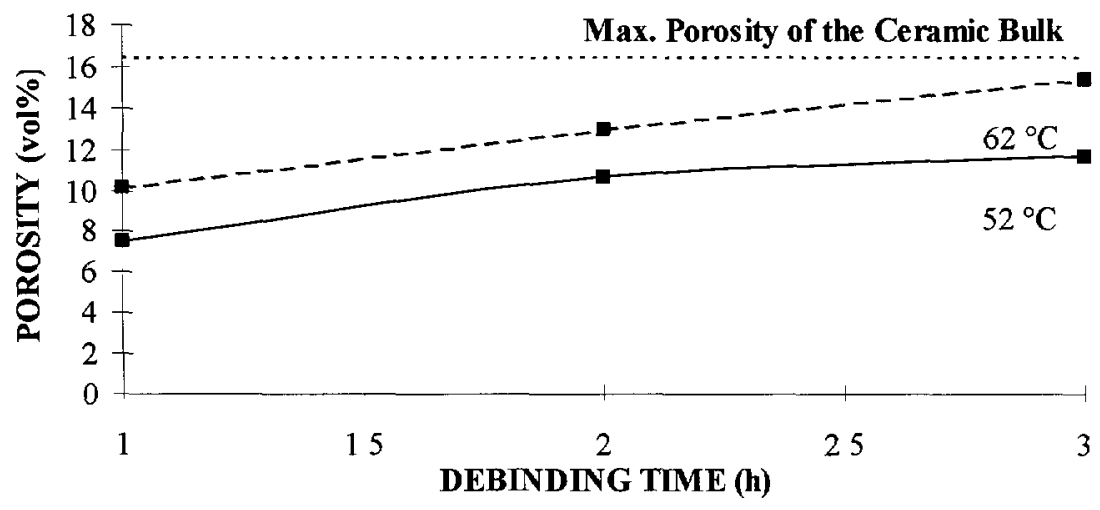

Fig. 10 - Evolution of the porosity with debinding time at $52{ }^{\circ} \mathrm{C}$ and $62{ }^{\circ} \mathrm{C}$

the pore wall, $R_{1}$ is the radius of a small pore and $R_{2}$ the radius of a larger pore.

Melted wax may thus be drained from large pores within the samples to small pores near the surface during binder extraction.

4.4. Porosity Development. - The evolution of the porosity during debinding will depend on the mechanisms of organic removal and should thus be different between the solid state at $52^{\circ} \mathrm{C}$ and the liquid state at $62^{\circ} \mathrm{C}$ or $72^{\circ} \mathrm{C}$.

In order to determine how the porosity develops during wax extraction, samples are debinded under $28 \mathrm{MPa}$, at 52 and $62{ }^{\circ} \mathrm{C}$, for one, two and three hours. In parallel with these experiments, another sample is completely thermally debinded (with an heating rate of $1^{\circ} \mathrm{C} \mathrm{min}^{-1}$ up to $200^{\circ} \mathrm{C}$, an hold up time of 4 hours and a final heating rate of $1^{\circ} \mathrm{C} \mathrm{min}-1$ up to $500^{\circ} \mathrm{C}$ before cooling) to evaluate the final pore size distribution of the ceramic injected bulk.

Pore size distributions of debinded samples are measured by mercury porosimetry and given in Figures 6,7 and 8. Depending on the temperature, the evolution of the opening of the porosity is different. At $52{ }^{\circ} \mathrm{C}$, small pores are first opened whereas large pores appear first at $62{ }^{\circ} \mathrm{C}$. Two classes of pores can be distinguished at both temperatures, one ranging from about 0.1 to $0.7 \mu \mathrm{m}$, the other one ranging from about 07 to $5 \mu \mathrm{m}$. If the following ratio, volume of pores between 0.7 and $5 \mu \mathrm{m}$ over volume of pores between 0.1 and $0.7 \mu \mathrm{m}$, is plotted as a function of the debinding time (Fig. 9), it becomes evident that the opening of porosity differs completely between the two temperatures tested.

At $52{ }^{\circ} \mathrm{C}$, evacuation of solubilised wax molecules by diffusion only opens small channels (the median "channel" diameter is equal to $0.39 \mu \mathrm{m}$ ) in the binder phase located in the largest pores between the ceramic particles. As wax molecules are further removed during the treatment, these largest pores (with a median diameter of $1.5 \mu \mathrm{m}$ ) become entirely open. Then, during the third hour of treatment, new small pores appear which can correspond to the smallest pores of the green body (Fig. 6).

At $62{ }^{\circ} \mathrm{C}$ however, it becomes obvious that capillary flow occurs and combines with diffusion. The smallest pores remain filled up with binder whereas bigger ones open. After one hour of extraction, the $0.7-5 \mu \mathrm{m}$ pore class is far more developed than the smaller one: the median pore diameter is equal to $2.8 \mu \mathrm{m}$ (to compare with the $0.39 \mu \mathrm{m}$ value obtained at $52{ }^{\circ} \mathrm{C}$ after 1 hour). Pore size distribution corresponding to two hours of extraction is difficult to explain as pores develop due to both capillary flow and diffusion. This distribution suggests that capillary migration open large pores and diffusion of solubilised polymer by supercritical $\mathrm{CO}_{2}$ 
open small ones. During the third hour of extraction, capillary migration may become less important than diffusion as more than $70 \mathrm{wt} . \%$ of the organic phase mainly located in large pores is removed and small open pores become larger due to the diffusion process of solubilised species.

In our case, the porosity has nearly completely opened at $62{ }^{\circ} \mathrm{C}$ whereas roughly $70 \%$ of the porosity is opened at $52{ }^{\circ} \mathrm{C}$ (Fig. 10).

\section{Conclusion}

In a previous study [1] on supercritical debinding of ceramics, two mechanisms of extraction of organic additives in a solid state, namely solubilisation of binder molecules and diffusion of solvato-complexes, were found to involve in the extraction process and a model based on diffusion equations was developed.

In the presence of a low melting point binder system however, a third mechanism of removal based on capillary flow is activated when the temperature of extraction is higher than the melting point of the organic phase. Porosity development in the sample during debinding confirms that, in this case, a liquid phase redistribution, governed by the differences in capillary pressure between pores of different sizes, occurs in the green body.

The diffusion model developed remains in good agreement with experimental results for a temperature treatment below the melting point of the binder. But this model will have to be completed with a capillary migration term to fit the results obtained at a temperature above the melting temperature.

Finally, the contribution of capillary flow allows faster extraction rates. A too important liquid phase however induces sample deformation. Optimisation of supercritical fluid extraction cycles will thus need to facilitate but to control the evolution of such a liquid phase to avoid deformation of the green part.

\section{References}

[1] Chartier T., Ferrato M. and Baumard J.F., Supercritical Debinding of Injection Molded Ceramics, J. Am. Ceram. Soc. 78 (1995) 1787-92.

[2] Chartier T., Ferrato M. and Baumard J.F., Influence of the Debinding Method on the Mechanical Properties of Plastic Formed Ceramics, J. Eur. Ceram. Soc. 15 (1995) 899-903.

[3] Zangh J.G., Edirisinghe M.J. and Evans J.R.G., A Catalogue of Ceramic Injection Moulding Defects and their Causes, Ind. Ceram. 9 (1989) 72-82.

[4] Lange F.F., Davis B.I. and Wright E., J. Processing Related Fracture Origins: IV, Elımınation of Voids Produced by Organic Inclusions, J. Am. Ceram. Soc. 69 (1989) 66-69.

[5] Bennison S.J. and Harmer M.P., Swelling of Hot-pressed Alumina, J. Am Ceram. Soc. 68 (1985) 591-596.

[6] Dong C. and Bowen H.K., Hot Stage Bubble Formation during Binder Burnout, J. Am. Ceram. Soc. 72 (1989) 1082-1087.

[7] Pinmill I.E., Edirisinghe M J. and Bevis M.J., Development of Temperature Heating Rate Diagrams for the Pyrolytic Removal of Binder used for Powder Injection Moulding, J. Mat. Sci. 27 (1992) 4381-4388. 
[8] Rosset R. and Perrut M., La Chromatographie avec éluant supercritique, in Proceedings on Supercritical Fluids (INPL press Eds., Nancy, France, 1987) p. 305-322.

[9] Miyashita T., Ueno Y. and Kubodera S., Method for Removing the Dispersion Medium from a Molded Pulverulent Material, U.S.Pat. n²437332 (1988).

[10] Nakashima N., Nishikawa E. and Wakao N., Binder Removal from a Ceramic Green Body in the Environment of Supercritical Carbon Dioxide with/without Entramers, in Proceedings of the $2^{\text {nd }}$ International Symposium on Supercritical Fluids (M. McHugh, Butterworth Publishers, Boston, 1991) p. 357-359.

[11] Crank J., The Mathematics of Diffusion, $2^{\text {nd }}$ edition (Clarendon Press, 1975) p. 49.

[12] Hawthorne S.B., Analytical Scale Supercritical Fluid Extraction, Anal. Chem. 62 (1990) 633A-642A.

[13] Sassiat P.R., Mourier P., Caude M.H. and Rosset R.H., Measurement of Diffusion Coefficients in Supercritical Carbon Dioxide and Correlation with the Equation of Wilke and Chang, Anal. Chem. 59 (1987) 1164-1170.

[14] Cima M.J., Dudziak M. and Lewis J.A., Observation of Poly(Vinyl Butyral) - Dibutyl Phtalate Binder Capillary Migration, J. Am. Ceram. Soc. 72 (1989) 1087-1090. 